\title{
Ocorrência de Hepatozoon sp. em caninos naturalmente infectados no município de Piraí, Rio de Janeiro, Brasil
}

\author{
Occurrence of Hepatozoon spp. in naturally infected dogs \\ from Piraí, Rio de Janeiro, Brazil
}

\begin{abstract}
Ananda Müller Pereira, ${ }^{*}$ Aloysio de Mello Figueiredo Cerqueira, ${ }^{* *}$ Pedro Bittencourt Velho, ${ }^{*}$ Alexandre Garcia de Sá***, Renata Fernandes Ferreira, ${ }^{*}$ Daniel de Barros Macieira, ${ }^{*}$ Namir Santos Moreira, ${ }^{*}$ Camila Nunes Fonseca, ${ }^{*}$ Marcia de Souza Xavier, ${ }^{*}$ Suzana Gomes Leite, ${ }^{*}$ Renata Rezende Guedes Correia de Oliveira, ${ }^{*}$ Nádia Regina Pereira Almosny
\end{abstract}

\begin{abstract}
Resumo
Hepatozoon canis tem sido descrito em cães de várias regiões do Brasil sendo mais relatado em áreas rurais. O objetivo deste trabalho foi determinar a ocorrência de infecção por Hepatozoon spp. através da reação em cadeia da polimerase (PCR), em cães de região periurbana da cidade de Piraí, RJ. Em setembro/2006, foram coletadas amostras de sangue de 88 cães da cidade, situada no vale do rio Paraíba do Sul. A PCR foi utilizada para a detecção de Hepatozoon spp. (gene 18SRNAr) através de um par de iniciadores gênero-específicos. Duas amostras apresentaram resultado PCR-positivo $(2,2 \%)$, havendo concordância com a avaliação morfológica em esfregaços sanguíneos. A amostra de Piraí demonstrou alta similaridade (99\%) com Hepatozoon canis. Os cães de Piraí apresentaram baixa frequência de infecção por $H$. canis, quando comparados a pesquisas anteriores na mesma região.
\end{abstract}

Palavras-chave: Hepatozoon spp., cães, PCR, diagnóstico.

\begin{abstract}
In Brazil Hepatozoon canis infection seems to occur more often in rural areas. The aim of this study was to estimate the occurrence of Hepatozoon spp. infections in Piraí, situated in Paraíba do Sul region from Rio de Janeiro, Brazil, through polymerase chain reaction (PCR). In September/2006, blood samples of 88 dogs with no clinical signs of disease were collected. PCR was used to detect Hepatozoon spp. DNA (from 18S rRNA gene) using a genus-specific primer set. Two samples had a positive PCR result $(2,2 \%)$. Morphological evaluation of blood films detected the parasite in these two animals. According to the sequencing Piraí's isolate had high similarity $(99 \%)$ to Hepatozoon canis. Low rates of Hepatozoon sp. infection were observed on dogs from Piraí.
\end{abstract}

Keywords: Hepatozoon spp., dogs, PCR, diagnosis.

\section{Introdução}

A hepatozoonose canina (Bentley, 1905) é causada pelo protozoário Hepatozoon spp. (Baneth e Shkap, 2003) e tem o carrapato como vetor. O Gênero Hepatozoon compreende protozoários pertencentes ao filo Apicomplexa, família Hepatozoidae, subordem Adeleorina (Wenyon, 1926).

No cão a doença pode ser causada por duas espécies de Hepatozoon: $H$. americanum, agente descrito somente nos Estados Unidos da América (EUA) (Vincent-Johnson et al., 1997) e $H$. canis, que causa a hemoparasitose nos outros países (Baneth et al., 2000), tendo sido recentemente descrito infectando cães nos EUA (Allen et al., 2008). H. canis é mais adaptado ao cão. Hepatozoon americanum pode ser considerado um parasita emergente com alta virulência e que parece ter atravessado a barreira entre espécies recentemente a partir de um hospedeiro silvestre (Baneth, 2006).

$O$ vetor mundialmente conhecido pela transmissão de $H$. canis é o carrapato R. sanguineus (Chistophers, 1907; Baneth et al., 2001). No Japão o carrapato Haemophysalis spp. foi descrito como provável vetor (Murata et al., 1995). No Brasil, espécies de Amblyoma ( $A$. aureolatum, $A$. cajennense e $A$. ovale) são incriminadas na transmissão (Massard, 1979; O'Dwyer et al., 2001; Forlano et al., 2005), embora $R$. sanguineus tenha sido encontrado infestando cães infectados por H. canis (Rubini et al., 2008).

No Brasil a hepatozoonose canina foi descrita pela primeira vez em cães de áreas rurais do estado do Rio de Janeiro (Massard, 1979) e estudos moleculares recentes demons-

\footnotetext{
* Departamento de Patologia e Clínica Veterinária, Universidade Federal Fluminense (UFF), Rua Vital Brazil Filho 64, Santa Rosa, Niterói, RJ 24230-340, Brasil. Autor para correspondência: E-mail: ananda_muller@yahoo.com.br

** Departamento de Microbiologia e Parasitologia, Instituto Biomédico, Universidade Federal Fluminense (UFF), Rua Prof. Ernani Pires de Melo 101, Centro, Niterói, RJ 24210-130.

*** Laboratório Vet Análises, Rua Ipiranga, 53, Laranjeiras, Rio de Janeiro, RJ 22231-120, Brasil.
} 
traram que a espécie descrita infectando cães é $H$. canis (Paludo et al., 2005; Rubini et al., 2005; Forlano et al., 2007; Rubini et al., 2008).

A infecção por $H$. canis ocorre em regiões de clima tropical, subtropical e temperado, sendo sua distribuição diretamente relacionada com a presença do vetor artrópode. No Brasil, a infecção por Hepatozoon sp. parece ocorrer mais frequentemente em cães de áreas rurais (31,58\%), do que em cães de áreas urbanas (4,48\%) (Massard, 1979). Cães de áreas rurais têm acesso livre a florestas e outros ambientes, onde diferentes espécies de animais silvestres e domésticos estão presentes. Nestas condições, os cães podem ser infestados por diferentes espécies de carrapatos e diferentes agentes (Labruna e Campos Pereira, 2001).

$H$. canis foi encontrado em cães sadios na África (Ezekoli et al., 1983), Japão (Murata et al., 1993), Israel (Baneth et al., 1996) e Brasil (Mundim et al., 1994; Gondim et al., 1998; Paludo et al., 2005; Spolidoro et al., 2009). As alterações clínicas parecem estar relacionadas com a presença de infecções concomitantes (Murata et al., 1991; Harmelin et al., 1992), imunossupressão (Gosset et al., 1985) e grau de parasitismo (Baneth e Weigler, 1997). Os sinais clínicos da hepatozoonose parecem ser pouco específicos (O’Dwyer e Massard, 2001).

O diagnóstico de infecção por $H$. canis realizado rotineiramente é por meio de avaliação morfológica de neutrófilos e monócitos à procura de gamontes em esfregaço de sangue periférico corado por método Giemsa (Ibrahim et al., 1989; Baneth et al., 1996; Baneth e Weigler, 1997). Existem ainda, testes sorológicos como a imunofluorescência indireta (Shkap et al., 1994) e o ELISA (Gonen et al., 2004). A técnica da reação em cadeia da polimerase (PCR) pode ser utilizada tanto no diagnóstico da hepatozoonose como em estudos epidemiológicos (Eiras et al., 2007), tendo como principais vantagens sensibilidade e a especificidade para a detecção de patógenos no sangue e em artrópodes vetores (Inokuma et al., 2002; Rubini et al., 2005; Karagenc et al., 2006).

O objetivo deste trabalho foi determinar a ocorrência de infecção por Hepatozoon spp. através da PCR em cães de Piraí, RJ.

\section{Material e métodos}

Foram utilizados 88 cães, correspondentes a aproximadamente $2,79 \%$ da população canina da cidade de Piraí. A população canina foi estimada de acordo com a Organização Mundial de Saúde (World Health Organization, 1990), que estabelece uma proporção de 1 cão para cada 7 habitantes em países emergentes. A população humana da região de Piraí, segundo o IBGE no ano de 2000, era de 22.118 habitantes; assim, estimou-se o valor de aproximadamente 3.160 cães na região. Os cães do presente estudo foram escolhidos aleatoriamente, independentemente de idade, sexo, raça ou condição corporal durante a Campanha de Vacinação Antirrábica no município de Piraí (22 $27^{\prime} 58^{\prime \prime} \mathrm{S}$, $43^{\circ} 49^{\prime} 40^{\prime \prime}$ W), RJ, durante o mês de setembro de 2006. O posto de vacinação escolhido atendeu animais pertencentes à população de área periurbana. As amostras foram obtidas após consentimento, por escrito, do proprietário.
Foram coletadas amostras de sangue e, dos animais infestados, amostras de carrapatos. O sangue foi coletado por meio de venopunção cefálica e acondicionado em tubos contendo anticoagulante (EDTA). Foram realizados esfregaços sanguíneos imediatamente após a coleta. Foi realizada pesquisa de Hepatozoon spp. por avaliação morfológica de esfregaços sanguíneos corados pelo Giemsa $\left(\right.$ Merck $\left.^{\circledR}\right)$. Em 12 cães observou-se infestação por carrapatos e estes artrópodes foram coletados para posterior classificação sistemática na Fundação Oswaldo Cruz (Fiocruz).

As amostras de sangue foram transportadas sob refrigeração (4ํㅡ) para o Laboratório de Bactérias Enteropatogênicas e Microbiologia de Alimentos, no Instituto Biomédico da Universidade Federal Fluminense, onde foram congeladas em freezer $-20^{\circ} \mathrm{C}$ até posterior extração/purificação do DNA.

As amostras de sangue total tiveram seu DNA extraído utilizando-se o GFX ${ }^{\mathrm{TM}}$ Genomic Blood Purification Kit (Amersham Biosciences, Piscataway, EUA) de acordo com as instruções do fabricante. Foi escolhido o método direto, utilizando $100 \mu \mathrm{L}$ de sangue total, sendo o DNA obtido eluído em $100 \mu \mathrm{L}$ de água "UltraPure ${ }^{\mathrm{TM}}$ DNase/RNase-Free Distilled Water" (Gibco/Invitrogen, Carlsbad, EUA). O DNA extraído foi armazenado a $-20^{\circ} \mathrm{C}$ até o momento da sua utilização para a PCR. Com o objetivo de se verificar a possibilidade de contaminação durante a extração do DNA genômico, na última amostra extraída, em cada dia, o sangue total era substituído por água "UltraPure ${ }^{\mathrm{TM}}$ DNase/RNase-Free Distilled Water" (Gibco/Invitrogen, Carlsbad, EUA).

O DNA extraído de cada amostra foi testado para o gene codificador da enzima gliceraldeído-3-fosfato desidrogenase (GAPDH), usado como verificador para a presença de DNA amplificável na amostra, uma vez que é encontrado em todos os mamíferos, resultando na formação de um produto de 399 pares de base (Birkenheuer et al., 2003). Todas as amostras cuja presença de DNA amplificável for comprovada através da PCR previamente descrita foram testadas para a presença de sequência genética da maioria das espécies do gênero Hepatozoon utilizando-se os iniciadores ou "primers" HEPF ("foward") e HEPR ("reverse") conforme descrito por Inokuma et al. (2002), os quais permitem a amplificação de um fragmento do gene 18S RNAr, originando um produto de aproximadamente 625 pares de base (pb).

Para confirmação da validade dos resultados da PCR foi utilizada uma amostra de DNA genômico obtido de um cão naturalmente infectado por $H$. canis.

Estimativas de ocorrência foram calculadas para os animais testados para a presença de Hepatozoon spp.

Uma amostra positiva para Hepatozoon spp., a partir dos iniciadores HEPF e HEPR, foi purificada com o Kit PureLink ${ }^{T M}$ PCR Purification Kit (Invitrogen ${ }^{\circledR}$ ), de acordo com as instruções do fabricante, para sequenciamento. $O$ sequenciamento dos produtos amplificados a partir de sangue total de cão foi realizado no sentido sense e antisense direções, com concentração de DNA inicial de 2040ng, combinados com o par de primers (Foward e Reverse) utilizados na reação de amplificação. O sequenciamento foi realizado na plataforma de sequenciamento da Embrapa, CENARGEN, Brasília, Brasil. 
As sequências obtidas a partir do produto de $625 \mathrm{pb}$ foram editadas no programa BIOEDIT ${ }^{\circledR}$ 5.0.9., para obtenção de sequência consensual que foi cadastrada no Gene Bank, com número de acesso (GQ176285).

\section{Resultados e discussão}

Dos 88 cães testados do município de Piraí, dois foram positivos para Hepatozoon spp. na PCR, havendo concordância com a avaliação morfológica em esfregaços sanguíneos, onde apenas dois animais foram também positivos. Dentre os dois animais positivos por PCR, um foi selecionado para sequenciamento.

A sequência consensual de nucleotídeos do produto de $625 p b$ da PCR do presente trabalho (GQ176285), excluindo as regiões dos iniciadores, foi utilizada para a pesquisa de sequências homólogas no Genbank. O isolado de Piraí demonstrou alta similaridade (99\%) com Hepatozoon canis descrito em cães de São Paulo, (FJ743476), Porto Alegre (EU571737), Brasil (FJ943578), Recife (FJ943578), Croácia (FJ497021) e Japão (AF418558). Estudos de caracterização filogenética das amostras brasileiras (Paludo et al., 2005; Rubini et al., 2005; Forlano et al., 2007; Rubini et al., 2008) têm observado, assim como no presente trabalho, a ocorrência de $H$. canis no Brasil.

Os cães positivos do presente estudo também estavam positivos na avaliação morfológica dos esfregaços sanguíneos, com parasitemia menor que $1 \%$. Animais com baixa parasitemia por Hepatozoon spp. parecem não apresentar alterações clínicas, e esse quadro se inverte com o aumento da parasitemia (Baneth e Weigler, 1997; Karagenc et al., 2006). Por outro lado, $H$. canis vem sendo considerado um parasita de baixa patogenicidade (McCully et al., 1975), uma vez que mesmo quando os gamontes são encontrados em esfregaços sanguíneos, os diversos sinais clínicos vêm sendo atribuídos a infecções associadas a outros patógenos mais potentes, como Babesia canis, Ehrlichia canis e Leishmania sp. (Rioux et al., 1964; Ogunkoya et al., 1981; Gossett et al., 1985; Kontos e Koutinas, 1997). Infecções por hemoparasitas sem sintomatologia sugerem maior adaptação parasita hospedeiro. Além disso, a infecção nem sempre determina desenvolvimento de doença nos indivíduos.

A ocorrência de Hepatozoon spp. por meio da PCR em Piraí foi de $2,2 \%$, diferente das altas prevalências observadas por Massard (1979), (31,58\%) e O'Dwyer et al. (2001) (39,2\%) em áreas rurais do Rio de Janeiro. Estudos anteriores em Piraí (O'Dwyer et al., 2001) demonstraram $59,4 \%$ de cães naturalmente infectados. É importante ressaltar que, no presente trabalho, foram avaliados cães provenientes de área periurbana de Piraí, fato este que pode justificar a baixa ocorrência do parasita, uma vez que aqueles autores pesquisaram áreas rurais. Por outro lado, no estado do Espírito Santo não houve diferença significativa entre a ocorrência de Hepatozoon spp. em áreas rurais ou urbanas (Spolidorio et al., 2009). Em outras regiões do Brasil a ocorrência deste hemoparasita foi variável, sendo encontrada 58,7\% no Espírito Santo (Spolidorio et al., 2009),
$4,48 \%$ e $8,3 \%$ em regiões urbanas do estado do Rio de Janeiro (Massard, 1979; Sá et al., 2007), 5,9\% em áreas urbanas do estado São Paulo (O'Dwyer et al., 2004) e 11,4\% (Rubini et al., 2008) em áreas rurais do mesmo Estado. Esta variação tem sido descrita na literatura mundial (Ezekoli et al., 1983; Rajamanickam et al., 1985; Oyamada et al., 2005; Rubini et al., 2005; Karagenc et al., 2006; Yabsley et al., 2007; Sasaki et al., 2008).

Quanto aos carrapatos, $13,7 \%$ dos cães estavam infestados. Baixas taxas de infestação por carrapatos (24\%) em cães de áreas rurais de São Paulo também foram reportadas (Rubini et al., 2008). Os resultados obtidos no presente estudo provavelmente refletem o hábito de banhar os animais antes de levá-los à vacinação, o que deve ter ocorrido na campanha de vacinação de Piraí.

Após a classificação sistemática, observou-se que todos os 12 carrapatos infestando cães de Piraí pertenciam à espécie Rhipicephalus sanguineus. Este ixodídeo é comumente encontrado no ambiente urbano (Labruna e Campos Pereira, 2001), sendo menos abundante em áreas rurais (Szabó et al., 2001). Cães de áreas rurais, com movimentação livre, são infestados principalmente por espécies do gênero Amblyomma (Massard, 1979; Labruna e Campos Pereira, 2001; O'Dwyer et al., 2001), diferente do que foi encontrado no presente estudo. O local de coleta das amostras tratavase de região periurbana de Piraí, já com desmatamento e urbanização, fato este que pode ter favorecido o aparecimento somente de $R$. sanguineus. Entretanto, não se pode descartar a possibilidade de infestações anteriores por outros gêneros de carrapatos.

A confirmação dos prováveis vetores da hepatozoonose canina no Brasil tem sido um tema controverso (Spolidorio et al., 2009). Amblyomma ovale foi caracterizado como vetor em infecção experimental no Rio de Janeiro (Forlano et al., 2005; Forlano et al., 2007). Por outro lado, alguns estudos demonstraram cães infectados por $\mathrm{H}$. canis infestados por Amblyomma spp. e R. sanguineus (O'Dwyer et al., 2001; Rubini et al., 2008) e o carrapato Rhipicephalus sanguineus foi considerado o principal vetor no mundo, com infecção experimental demonstrada (Baneth et al, 2001). Possivelmente, tanto $R$. sanguineus como algumas espécies de Amblyomma têm um importante papel na transmissão de $H$. canis no Brasil (Spolidoro et al., 2009). Os dois animais positivos para $H$. canis de Piraí estavam infestados por $R$. sanguineus.

\section{Conclusões}

Hepatozoon canis está presente na população canina da região periurbana do município de Piraí, vale do Rio Paraíba do Sul, Rio de Janeiro.

Os cães de Piraí apresentaram baixa frequência de infecção por $H$. canis, quando comparados a pesquisas anteriores no mesmo município.

Como o carrapato $R$. sanguineus foi a única espécie detectada, é provável que este atue como vetor de Hepatozoon spp. em cães na região. 


\section{Agradecimentos}

Ao apoio dos órgãos de fomento FAPERJ, CAPES e CNPq. Agradecemos à Profa. Dra. Lucia Helena O'Dwyer, da Universidade Estadual Paulista, Campus de Botucatu, SP, Brasil, que gentilmente cedeu amostra controle positivo, imprescindível para a execução deste trabalho.

\section{Referências}

ALLEN, K.E.; LI, Y.; KALTENBOECK, B.; JOHNSON, E.M.; REICHARD, M.V.; PANCIERA, R.J.; LITTLE, S.E. Diversity of Hepatozoon species in naturally infected dogs in the southern United States. Vet. Parasitol., v.154, p. 220-225, 2008.

BANETH, G.; SHKAP, V.; PRESENTEY, B. Hepatozoon canis: The prevalence of antibodies and gametocytes in dogs in Israel. Vet. Research Commun.,v. 20, p. 41-46, 1996.

BANETH, G.; WEIGLER, B. Retrospective case-control study of hepatozoonosis in dogs in Israel. J. Vet. Intern. Med., v. 11, p. 365370, 1997.

BANETH, G.; BARTA, J. R.; SHKAP, V.; MARTIN, D. S.; MANCITIRE, D. K.; VICENT-JOHNSON, N. Genetic and antigenic evidence supports the separation of Hepatozoon canis and Hepatozoon americanum at the species level. J. Clin. Microbiol., v. 38, n. 3, p. 1298-301, 2000.

BANETH, G.; SAMISH, M.; ALEKSEEV, E.; AROCH, I.; SHKAP, V. Transmission of Hepatozoon canis to dogs by naturally-fed or percutaneosly-injected Rhipicephalus sanguineus ticks. J. Parasitol., v. 87, p. 606-611, 2001.

BANETH, G.; SHKAP, V. Monozoitic cysts of Hepatozoon canis. J. Parasitol., v. 89, p. 379-381, 2003.

BANETH, G. Hepatozoon canis Infection, In: GREENE, C. E. (Ed.). Infectious Diseases of the Dog and Cat. Canada: W.B. Saunders, 2006, p. 698-711.

BENTLEY, C.A. Preliminary note upon a Leucocytozoon of the dog. Brit. Med. J., v. 1, p. 1018, 1905.

BIRKENHEUER, A. J.; LEVI, M. G.; BREITSCHWERDT, E. Development and evaluation of a seminested PCR for detection of Babesia gibsoni (Asian genotype) and B. canis DNA in canine blood samples. Journal of Clinical Microbiology, v. 41, p. 4172- 4177, 2003.

CHRISTOPHERS, S.R. The sexual life of the Leucocytozoon canis in the tick. Scientific Memoirs Officers of the Medical Sanitary Depepartments Government of India, v. 28, p. 11, 1907.

EIRAS, D.F;BABASE, J; SCODELLARO, C.F; BANACH, D.B; MATOS, M.L; KRIMER, A.; BANETH, G. First molecular characterization of canine hepatozoonosis in Argentina: Evaluation of asymptomatic Hepatozoon canis infection in dogs from Buenos Aires. Vet. Parasitol., v. 149, p. 275-279, 2007.

EZEKOLI, C.D.; OGUNKOYA, A.B.; ABDULLAHI, R.; TEKDEK, L.B.; SANNUSI, A.; ILEMOBADE, A.A. Clinical and epidemiological studies on canine hepatozoonosis in Zaria, Nigeria. J. Small Anim. Pract., v. 24, p. 455-460, 1983.

FORLANO, M.; SCOFIELD, A.; ELISEI, C.; FERNANDES, K.R.; EWING, S. A.; MASSARD, C.L. Diagnosis of Hepatozoon spp. in Amblyomma ovale and its experimental transmission in domestic dogs in Brazil. Vet. Parasitol., v. 134, p. 1-7, 2005.

FORLANO, M.D.; TEIXEIRA, K.R.S.; SCOFIELD, A.; ELISEI, C.; YOKOTO, K.S.C.; FERNANDES, K.R.; LINHARES, G.F.C.; EWING, S.A.; MASSARD, C.L. Molecular characterization of Hepatozoon sp. from Brazilian dogs and its phylogenetic relationship with other Hepatozoon spp. Vet. Parasitol., v. 145, p. 21-30, 2007.

GONDIM, L.F.P.; KONAYAGAWA, A.; ALENCAR, N.X.;BIONDO, A.W.; TAKAHIRA, R.F.; FRANCO, S.R.V. Canine hepatozoonosis in Brazil: Description of eight naturally occurring cases. Vet. Parasitol., v. 74, p. 319-323, 1998.
GONEN, L.; STRAUSS-AYALI, D.; SHKAP, V.; VINCENT-JOHNSON, N.; MACINTIRE, D.K.; BANETH, G. An enzyme-linked immunosorbent assay for antibodies to Hepatozoon canis. Vet. Parasitol., v. 122, p. 131-139, 2004.

GOSSETT, K.A.; GAUNT, S.D.; AJA, D.S. Hepatozoonosis and ehrlichiosis in a dog. J. Am. Anim. Hosp. Assoc., v. 21, p. 265-267, 1985.

HARMELIN, A.; DUBEY, J.P.; YAKOBSON, B.; NYSKA, A.; ORGAD, U. Concurrent Hepatozoon canis and Toxoplasma gondii infections in a dog. Vet. Parasitol., v. 43, n. 1/2, p. 131-136, 1992.

IBRAHIM, N.D.; RAHAMATHULLA, P.M.; NJOKU, C.O. Neutrophil myeloperoxidase deficiency associated with canine hepatozoonosis. Int. J. Parasitol., v. 19, n. 8, p. 915-918, 1989.

INOKUMA, H.; OKUDA, M.; OHNO, K.; SHIMODA, K.; ONISHINI, T. Analysis of the 18S rRNA gene sequence of a Hepatozoon detected in two japanese dogs. Vet. Parasitol., v. 106, p. 265-271, 2002.

KARAGENC, T.I.; PASA, S.; KIRI, G.; HOSGOR, M.; BILGIC, H.B.; OZON, Y.H.; ATASOY, A.; EREN H. A parasitological, molecular and serological survey of Hepatozoon canis infections in dogs around the Agean coast of Turkey. Vet. Parasitol., v. 135, p. 113-119, 2006.

KONTOS, V.J.; KOUTINAS, A.F. Clinical observations in 15 spontaneous cases of canine babesiosis. Canine Pract., v. 22, p. 30-34, 1997.

LABRUNA, M.B.; CAMPOS PEREIRA, M. Carrapato em cães no Brasil. Clín. Vet., v. 30, p. 24-32, 2001.

MASSARD, C.A. Hepatozoon canis (James 1905) (Adeleida: Hepatozoidae) cães do Brasil, com uma revisão do gênero em membros da ordem carnívora. 1979. 121 f. Tese (Mestrado)Universidade Federal Rural do Rio de Janeiro, 1979.

MCCULLY, R.M.;BASSOON, P.A.;BIGALKE, R.D.; DE VOS, V.; YOUNG, $E$. Observations on naturally acquired hepatozoonosis of wild carnivores and dogs in the Republic of South Africa. J. Vet. Res., v. 42, p. 117-134, 1975.

MUNDIM, A.V.; MUNDIM, M.J.S.; JENSEN, N.M.P.; ARAUJO, S.F. Hepatozoon canis: estudo retrospectivo de 22 casos de infecção natural em cães de Uberlândia, MG. Revta Cent. Ciênc. Biomed. Univ. Fed. Uberlândia, v. 10, p. 89-95, 1994.

MURATA, T.; SHIRAMIZU, K.; HARA, Y.; INOUE, M.; SHIMODA, K.; NAKAMA, S. First case of Hepatozoon canis infection of a dog in Japan. J. Vet. Med. Sci., v. 53, n. 6, p. 1097-1099, 1991.

MURATA, T.; SHINODA, K.; INOUE, M. Seasonal periodical appearance of Hepatozoon canis gamont in the peripheral blood. J. Vet. Med. Sci., v. 55, p. 877, 1993.

MURATA, T.; INOUE, M.; TAURA, Y.; NAKAMA, S.; ABE, H.; FUJISAKE, K. Detection of Hepatozoon canis oocyst from ticks collected from infected dogs. J. Vet. Med. Sci., v. 57, p. 111-112, 1995.

O'DWYER, L.H.; MASSARD, C.L. Aspectos gerais da hepatozoonose canina. Revta Clín. Vet., v. 31, p. 34-39, 2001.

O'DWYER, L.H.; MASSARD, C.L.; PEREIRA, J.C. Hepatozoon canis infection associated with dog thicks of rural areas of Rio de Janeiro state, Brazil. Vet. Parasitol., v. 94, p. 143-150, 2001.

O'DWYER, L.H.; SAITO, M.E.; HASEGAWA, M.Y.; KOHAYAGAWA, A. Tissue stages of Hepatozoon canis in naturally infected dogs from São Paulo, Brazil. Vet. Parasitol., v. 94, p. 143-150, 2004.

OGUNKOYA, A.B.; ADEYANJU, J.B.; ALIU, Y.O. Experiences with the use of Imizol in treating canine blood parasites in Nigeria. J. Small Anim. Pract., v. 22, p. 775-777, 1981. 
OYAMADA, M.; DAVOUST, B.; BONI, M.; DEREURE, J.; BUCHETON, B.; HAMMAD, A.; ITAMOTO, K.; OKUDA, M.; INOKUMA, H. Detection of Babesia canis rossi, B. canis vogeli, and Hepatozoon canis in dogs in a village of Eastern Sudan by using a screening PCR and sequencing methodologies. Clin. Diagn. Lab. Immunol., v. 12, n. 11, p. 1343-1346, 2005.

PALUDO, G.R.; FRIEDMANN, H.; DELL'PORTO, A.; MACINTIRE, D.K.; WHITLEY, E.M.; BOUDREAUX, M.K.; BANETH, G.;BLAGBURN, B.L.; DYKSTRA, C.C. Hepatozoon spp.: Pathological and partial 18S rRNA sequence analysis from three Brazilian dogs. Parasitol. Res., v. 97, p. 167-170, 2005.

RAJAMANICKAM, C.; WIESENHUTTER, E.; ZIN, F.M.D. The incidence of canine hematozoa in peninsular Malaysia. Vet. Parasitol., v. 17, p. $151,1985$.

RIOUX, J.A.; GOLVAN, Y.J.; HONIN, R. Hepatozoon canis and Leishmania canis infection in a dog in the sets area, France. Ann. Parasitol. Hum. Comp., v. 39, p. 131-135, 1964.

RUBINI, A.S.; PADUAN, K.S.; CAVALCANTE, G.G.; RIBOLLA, P.E.M.; O'DWYER, L.H. Molecular identification and characterization of canine Hepatozoon species from Brazil. Vet. Parasitol., v. 97, p. 91-93, 2005.

RUBINI, A.S.; PADUAN, K.S.; LOPES, V.V.A.; O'DWYER, L.H. Molecular and parasitological survey of Hepatozoon canis (Apicomplexa: Hepatozoidae) in dogs from rural area of São Paulo state, Brazil. Parasitol Res., v. 102, p. 895-899, 2008.

SÁ, A.G.; CERQUEIRA, A.M.F.; O'DWYER, L.H.; ABREU, F.S.; FERREIRA, R.F.; PEREIRA, A.M.; VELHO, P.B.;RUBINI, A.S.; ALMOSNY, N.R.P. Detection of Hepatozoon spp in naturally infected Brazilian dogs by polymerase chain reaction. Int. J. Appl. Res. Vet. Med., v. 5, n. 2, p. 49-51, 2007.
SASAKI, M.; OMOBOWALE, O.; OHTA, K.; TOZUKA, M.; MATSUU, A.; HIRATA, H.; NOTTIDGE, H. O.; IKADAI, H.; OYAMADA, T. A PCR-based epidemiological survey of Hepatozoon canis in dogs in Nigeria. J. Vet. Med. Sci., v. 70, n. 7, p. 743-745, 2008.

SHKAP, V.; BANETH, G.; PIPANO, E. Circulating antibodies to Hepatozoon canis demonstrated by imunofluorescence. J. Vet. Diagn. Invest., v. 6, p. 121-123, 1994.

SPOLIDORIO, M.G.; LABRUNA, M.B.; ZAGO, A.M.; DONATELE, D.M.; CALIARI, K.M.; YOSHINARI, N.H. Hepatozoon canis infecting dogs in the State of Espírito Santo, southeastern Brazil. Vet. Parasitol., v. 163, n.4, p. 357-361, 2009.

SZABO, M.P.J.; CUNHA, T.M.; PINTER, A.; VICENTINE, F. Ticks (Acari:Ixodidae) associated with domestic dogs in Franca region, São Paulo, Brazil. Exp. Appl. Acarol., v. 25, p. 909-916, 2001.

VINCENT-JOHNSON, N.; MANCITIRE, D.K.E.; BANETH, G. Canine hepatozoonosis: pathophysiology, diagnosis, and treatment. Compend. Contin. Educ. Pract. Vet., v. 19, n. 1, p. 51-62, 1997.

WENYON, C.M. (ed.). Protozoology - a manual for medical, men, veterinarians and zoologists. New York: W. Wood, 1926.

WORLD HEALTH ORGANIZATION. Guidelines for dog population management. Geneva, 1990.

YABSLEY, M. J.; MCKIBBEN, J.; MACPHERSON, C.N.; CATTAN, P.F.; CHERRY, N.A.; HEGARTY, B.C.; BREITSCHWERDT, E.B.; O'CONNOR, T.; CHANDRASHEKAR, R.; PATERSON, T.; PEREA, M.L.; BALL, G.; FRIESEN, S.; GOEDDE, J.; HENDERSON, B.; SYLVESTER, W. Prevalence of Ehrlichia canis, Anaplasma platys, Babesia canis vogeli, Hepatozoon canis, Bartonella vinsonii berkhoffii, and Rickettsia spp. in dogs from Grenada. Vet. Parasitol., v. 151, p. 279-285, 2008. 